\title{
Effects of Climate Change on the Potentially Suitable Climatic Geographical Range of Liriodendron chinense
}

\author{
Xiang $\mathrm{Xu}^{1}{ }^{1}$, , Huayong Zhang ${ }^{1, *}(\mathbb{D})$, Ting Xie ${ }^{1}$, Yao $\mathrm{Xu}^{1}$, Lei Zhao ${ }^{1,2,3}$ and Wang Tian ${ }^{1}$ \\ 1 Research Center for Engineering Ecology and Nonlinear Science, North China Electric Power University, \\ Beijing 102206, China; xuxiang229@163.com (X.X.); tingxie1995@163.com (T.X.); xy1737_cool@126.com (Y.X.); \\ zhaolei@ncepu.edu.cn (L.Z.); tianwang870822@163.com (W.T.) \\ 2 Department of Ecology and Evolutionary Biology, University of Kansas, Lawrence, KS 66045, USA \\ 3 Kansas Biological Survey, University of Kansas, Lawrence, KS 66047, USA \\ * Correspondence: rceens@ncepu.edu.cn; Tel.: +86-010-6177-3936
}

Received: 2 August 2017; Accepted: 17 October 2017; Published: 19 October 2017

\begin{abstract}
Identifying the potentially suitable climatic geographical range for Liriodendron chinense (L. chinense) and predicting its responses to climate change is urgently necessary, as L. chinense is an important tertiary relict tree species. In this study, we simulated the potentially suitable climatic habitat of L. chinense in China using maximum entropy (MaxEnt) modeling. We found that the MaxEnt model was highly accurate with an average training Area Under the Curve (AUC) value of 0.912. Annual precipitation and mean temperature of the driest quarter are the main factors controlling the geographical distribution of $L$. chinense. Currently, the suitable climatic habitat of $L$. chinense is mainly located in Southeastern China. Forecasted patterns of predicted suitable climatic habitat show a significant change by the 2050s and 2070s, suggesting that the suitable climatic habitat of L. chinense would shift north with future climate change, based on four Representative Concentrations Pathways for carbon dioxide $\left(\mathrm{CO}_{2}\right)$ emissions. The southern extent of the current distribution would become unsuitable for L. chinense, pointing to a threat of extinction and highlighting the urgent need for conservation within the next half century. The potentially suitable climatic habitat of L. chinense was predicted to move further north, but those habitat gains may be inaccessible because of dispersal limitations. Our unique findings offer a climatic suitability map for L. chinense in China, which can help to identify locations where L. chinense may already exist, but has not yet been detected; to recognize locations where L. chinense is likely to spread in the future given forecasted climate change; and to select priority areas for its introduction, cultivation, and conservation.
\end{abstract}

Keywords: species distribution model; maximum entropy modeling; Liriodendron chinense; climate change; suitable climatic habitat

\section{Introduction}

Biodiversity is generally accepted to be decreasing at an unprecedented rate [1,2]. Among the many reasons for this, climate change is often regarded as one of the most significant drivers of the loss in biodiversity as it influences the growth and reproduction of species, thereby determining the natural distribution of species [3-5]. The Intergovernmental Panel on Climate Change estimated that the average global temperature, which has increased by $0.85^{\circ} \mathrm{C}$ during the 20th century, will continue to increase by at least $0.3-1.7^{\circ} \mathrm{C}$ and at most by $2.6-4.8^{\circ} \mathrm{C}$ by 2100 [6]. This increase in temperature is often considered to negatively affect ecosystems, through habitat fragmentation, increases in disease outbreak frequencies, and increases in the extinction rate of endangered species [7-9], although some studies have also found positive impacts on some species [10]. Therefore, to clarify the specific effects of climate change on species, as well as to mitigate the possible negative effects of climate change 
on ecosystems and biodiversity, it is important to identify the distribution of species under current climatic conditions and expected future climate change [11,12].

Ecological niche models (ENMs) are essential tools for simulating the spatial distribution of species, identifying the ecological niche of species, and assessing potential responses of organisms to climate change [13-16]. ENMs generally use one of two model types: mechanistic or correlative models [17]. Mechanistic models use direct measurements of the dimensions of the species' fundamental niche to map current or future sites falling within species tolerance limits, without the confounding effects of accessibility and interacting species [18]. However, the inputting of parameters into the mechanistic model requires scientific expertise and essential resources, which are unavailable for many species [19]. This time involvement and the data-intensive requirements of the mechanistic model have limited its application [20]. In contrast, correlative models use readily available presence/absence or presence-only species occurrence data as well as spatial environmental data. This quick parameterization trait has led to the general use of correlative models [21]. Some authors have argued that correlative models can simulate species spatial distribution but cannot describe species niche because presence data do not indicate the fundamental niche of a species, but rather the realized niche $[17,22]$. Nevertheless, correlative models have been reported as the most effective approach to translating climate change projections into ecological consequences, and thus have been used for the majority of niche models [23,24]. Of the many correlative ENMs, the maximum entropy MaxEnt model, based on the principle of maximum entropy [25], has been widely used because of its stable and reliable predictions, even with incomplete data and small sample sizes [26-28].

As an ancient relic species of angiosperms, Liriodendron chinense (Hemsl.) Sarg. is an important hardwood species in subtropical China. Its wood is suitable for making furniture, and its leaves and bark can be used in pharmacy, meaning that L. chinense has irreplaceable economic and ecological values [29,30]. It is naturally widespread in the mountains at an elevation of $450-1800 \mathrm{~m}$ in Southern China, including Anhui, Chongqing, Fujian, Guangxi, Guizhou, Hubei, Hunan, Jiangxi, Shaanxi, Southeastern Sichuan, Yunnan, and Zhejiang, and Northern Vietnam [31,32]. It is planted and widely grown along main roads in the city and countryside areas of Southern China as a greening woody species [33]. Being endangered and occurring in small, isolated, and thinly scattered populations, L. chinense has been listed as one of the rare and endangered plants in China [31,34]. The decline and dieback of L. chinense have been observed in mountainous areas due to the impact of climate change and human activities [35]. Thus, identifying the potential geographical distribution of this species and predicting how climate change will affect its geographic range are necessary and meaningful.

The aims of this study were (1) to model the potentially suitable climatic geographical range of L. chinense in China under current climate conditions, (2) to identify the main factors determining the potentially suitable climate of L. chinense, and (3) to predict the potentially suitable climatic habitat change of L. chinense under future climate change scenarios. Our results will help to identify priority areas for the conservation of $L$. chinense in coming decades.

\section{Materials and Methods}

\subsection{Species Occurrence Records}

We collected herbarium specimens of $L$. chinense from the Global Biodiversity Information Facility (GBIF, http:/ / www.gbif.org/) and Chinese Virtual Herbarium (CVH, http:/ /www.cvh.ac.cn/). This collection process resulted in 244 presence records with longitude and latitude information. To avoid the spatial autocorrelation of species occurrence points, we converted those 244 presence records into 213 grid cells of 10 arc-minute resolution. We used the cut-off of 10 arc-minutes because a finer resolution was not reasonable due to the potential spatial error in the herbarium data [36-39], and because a coarser resolution would unduly decrease the number of presence points available for modeling species distribution [40]. After the process of spatial filtering, we then assigned the center coordinates of those 213 grid cells as the presence records. After removing one record falling 
outside the environmental layers, we finally obtained 212 presence points of L. chinense to model its geographical range of potentially suitable climate in China (Figure 1, Table S1).

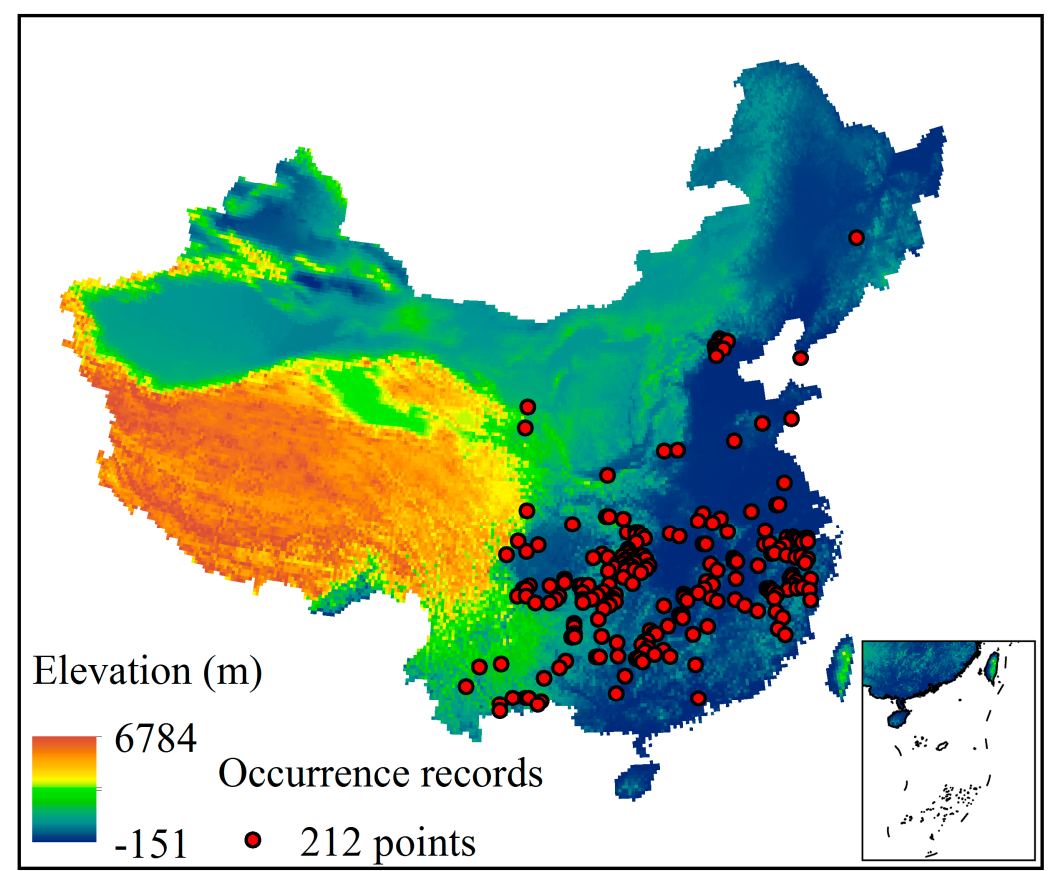

Figure 1. Spatial distribution of occurrence records and elevation of Liriodendron chinense in China.

\subsection{Environmental Variables}

We collected 23 environmental variables, including 19 bioclimatic and four topographical variables, to model the potentially suitable climatic geographical range of L. chinense (Table S2). Bioclimatic variables at 10 arc-minute resolution were extracted from the global database WorldClim [41], which were derived from monthly temperature and precipitation from global weather stations during the period of 1950 to 2000. Elevation variables were also extracted from WorldClim with a spatial resolution of 30 arc-seconds, so we resampled the elevation raster into 10 arc-minute grid cells. Slope, northness, and eastness were calculated based on elevation using ArcGIS 10.3 (ESRI, Redlands, CA, USA), and thus had a spatial resolution of 10 arc-minutes. Northness and eastness indicate a breakdown of slope aspect (0-360 degrees) into two linear variables: northness = cos(aspect) and eastness $=\sin ($ aspect) [42].

To predict the potentially suitable climatic habitat change under future climate change, we collected bioclimatic variables with a spatial resolution of 10 arc-minutes in the period of 2041-2060 (the 2050s) and 2061-2080 (the 2070s), based on the Intergovernmental Panel on Climate Change (IPCC) fifth assessment report from http:/ / www.worldclim.com. To reduce the uncertainty arising from the single general circulation model (GCM), we used data from multiple different GCMs [2,43,44] including BCC-CSM1-1, CCSM4, GISS-E2-R, IPSL-CM5A-LR, HadGEM2-ES, MIROC-ESM-CHEM, MRI-CGCM3, and NorESM1-M. For each GCM, we downloaded bioclimatic variables for four Representative Concentration Pathways (RCP: 2.6, 4.5, 6.0, and 8.5). We assumed that four topographical variables remain unchanged over the next 70 years. With this method, a total of 32 predictions were separately completed for L. chinense in the 2050s and 2070s. The future potential spatial distribution of L. chinense was obtained by averaging results using the ensemble approach from those predictions.

\subsection{Correlation Analysis and Principal Component Analysis}

Multicollinearity of variables may violate statistical assumptions and cause over-fitting in species distribution modeling [45], thus we removed the highly correlated variables. We calculated the 
Pearson correlation coefficient $(r)$ with the "Band Collection Statistics" tool in ArcGIS 10.3 to check the correlation among the 19 bioclimatic variables (the layers in Table S3) and four topographical variables (the layers in Table S4), respectively [15]. We also calculated the Pearson correlation coefficient $(r$ ) by the "cor" command in R to assess the correlation among the 19 bioclimatic variables (the points in Table S5) and four topographical variables (the points in Table S6) of the 212 species' occurrence records, respectively [46]. Those 19 bioclimatic and four topographical variables were extracted from the corresponding layers using the "Extract Multi Values to Points" tool in ArcGIS 10.3. If a pair of variables were highly correlated $(|r| \geq 0.7)$, only the most ecologically meaningful variable were kept [47]. We found that the four topographical variables were not highly correlated with each other, and therefore were all included in the MaxEnt modeling.

To determine the most meaningful ecological bioclimatic variables for L. chinense, we extracted 19 bioclimatic variables to the 212 species' occurrence points and then performed principal component analysis (PCA) on this 212 by 19 matrices using the "princomp" command in R. The first three principal components obtained with the PCA explained $47.2 \%, 21.5 \%$, and $14.6 \%$ of the variation in the spatial distribution of $L$. chinense respectively, for a total of $83.2 \%$ (Table S7). The bioclimatic variables with the highest factor loadings along the first three principal components were selected, including Bio8 (loading $=-0.509)$, Bio4 (loading $=-0.404)$, Bio9 (loading = 0.298), Bio12 (loading = 0.298), and Bio15 (loading $=-0.219)$ (Table S8; Figure S1).

However, variables irrelevant to species distribution may be also highly associated with the principal components, which may create a false expectation of their relevance for species distribution modeling [48]. Therefore, we needed to check the relevance between the selected five bioclimatic variables and species distribution using expert knowledge on the biological characteristics of the species [49,50]. Finally, we obtained the subset used for MaxEnt modeling, including temperature seasonality (TS), mean temperature of the wettest quarter (TWQ), mean temperature of the driest quarter (TDQ), annual precipitation (AP), precipitation seasonality (PS), elevation, slope, northness, and eastness.

\subsection{MaxEnt Model}

The potentially suitable climatic geographical range of L. chinense was simulated by using open access MaxEnt software (version 3.3.3) [26,51]. Based on 212 occurrence records and nine environmental variables, each MaxEnt run randomly selected $80 \%$ of the points to train the model, and the remaining $20 \%$ of the points to test and validate the model. The MaxEnt model was set to run with five replicates, subsample replicated run type, and 10,000 random background points [44,52,53]. The MaxEnt model limits its complexity by regularization, which is a penalty for including additional constraints (e.g., variables) in the model [54]. The MaxEnt software uses a regularization multiplier to control the intensity of regularization and assigns its default value of 1 . A lower regularization multiplier may result in an overfit prediction, while a higher value may result in a less discriminating prediction [26]. To select the most appropriate model, we compared different models built on a range of regularization multipliers: $0.5,1,2,3,4,5,6,7,8,9$, and 10 [40,54]. The best model was selected by the corrected Akaike information criterion (AICc) in the "ENMeval" package of R (R Core Team 2016, Vienna, Austria) [55,56]. The area under the receiver operating characteristic curve (AUC) was used to evaluate how well this MaxEnt model was able to predict presence and absence [51]. A jackknife test was then used to evaluate the most important factors determining the potentially suitable climatic geographical range L. chinense.

The results of the MaxEnt model predicted the probability (0-1 range) of the presence of L. chinense. To delineate the predicted presence/absence map of L. chinense, this continuous probability was converted into a binary prediction. A pixel was considered as either suitable or not for the species, based on a threshold probability indicative of species presence. This threshold probability was generated using the "maximum training sensitivity plus specificity" criteria, which has been proven to be one of the best threshold selection methods $[57,58]$. Sensitivity is the proportion of correctly 
predicted presences among all the presences, which is also called the true positive rate. Specificity is the proportion of correctly predicted absences among all the absences, which is also called the true negative rate. "Maximum training sensitivity plus specificity" optimizes the trade-off between sensitivity and specificity using the training data [59]. Those binary (suitable or not) distribution maps were then used to analyze the spatial range changes of L. chinense.

We analyzed the spatial range changes of L. chinense based on two aspects: changes in range area and range shifts along both latitudinal and longitudinal gradients. We defined "habitat gain" if the habitat was not suitable for L. chinense under current climate conditions but would become suitable in the future. If a habitat is suitable for L. chinense under the current climate but would no longer be suitable in the future, we called it "habitat loss". If a suitable habitat under the current climate would remain suitable for L. chinense in the future, we defined it as "unchanged". We then calculated the percentage of habitat gain or loss in the geographical range size of L. chinense between different time periods, which could lead to a conclusion of suitable climatic habitat contraction or expansion. To evaluate the latitudinal and longitudinal range shifts of L. chinense, we computed the centroids-the single central point - of the suitable climatic habitats of the current and future climate conditions using the "Zonal Geometry" tool in ArcGIS 10.3, and then calculated the difference in the centroids.

\section{Results}

\subsection{Model Evaluation and Contribution of the Variables}

The MaxEnt model for $L$. chinense provided satisfactory results, with an AUC value of $0.912 \pm 0.015$, which is higher than the 0.5 of a random model. The results of the jackknife test showed that AP and TDQ provided very high gains when used independently, indicating that AP and TDQ contained more useful information by themselves than the other variables (Figure S2). The cumulative contribution of these two variables was $88.1 \%$ (Table 1). Climatic variables cumulatively contributed $94.1 \%$ to the spatial distribution of L. chinense in China, while topographical variables contributed little, specifically $5.9 \%$.

Table 1. Environmental variables used in the maximum entropy (MaxEnt) model and their percentage contribution.

\begin{tabular}{|c|c|c|c|c|c|}
\hline Category & Variable & Description & Acronym & Unit & Contribution (\%) \\
\hline \multirow{5}{*}{ Climate } & Bio4 & $\begin{array}{l}\text { Temperature Seasonality } \\
\text { (Standard Deviation } \times 100 \text { ) }\end{array}$ & TS & ${ }^{\circ} \mathrm{C}$ & 6.7 \\
\hline & Bio8 & $\begin{array}{l}\text { Mean Temperature of } \\
\text { Wettest Quarter }\end{array}$ & TWQ & ${ }^{\circ} \mathrm{C}$ & 1.0 \\
\hline & Bio9 & $\begin{array}{l}\text { Mean Temperature of } \\
\text { Driest Quarter }\end{array}$ & TDQ & ${ }^{\circ} \mathrm{C}$ & 33.6 \\
\hline & Bio12 & Annual Precipitation & $\mathrm{AP}$ & $\mathrm{mm}$ & 49.1 \\
\hline & Bio15 & $\begin{array}{l}\text { Precipitation Seasonality } \\
\text { (Coefficient of Variation) }\end{array}$ & PS & Fraction & 3.7 \\
\hline \multirow{4}{*}{ Topography } & Elevation & & & $\mathrm{m}$ & 2.9 \\
\hline & Slope & & & $\circ$ & 2.7 \\
\hline & Northness & & & Dimensionless & 0.2 \\
\hline & Eastness & & & Dimensionless & 0.1 \\
\hline
\end{tabular}

\subsection{Response of Variables to Suitability}

The suitable climate of L. chinense was hump-shaped, with increasing TS, TWQ, TDQ, AP, and PS (Figure S3). However, the climatic suitability monotonically decreased with increasing elevation, 
whereas it monotonically increased with increasing slope. TDQ ranged from $-2.3^{\circ} \mathrm{C}$ to $17.1^{\circ} \mathrm{C}$ and AP ranged from $710 \mathrm{~mm}$ to $2875 \mathrm{~mm}$, which are suitable for the spatial distribution of L. chinense.

\subsection{Current Potential Geographical Range of Suitable Climate}

Maximum training sensitivity plus specificity was applied to the presence probability of L. chinense, derived from the MaxEnt model, and the generated value of 0.215 was the threshold probability of presence. The predicted binary distribution map of L. chinense, with presence-only data and current climatic conditions with MaxEnt modeling, is shown in Figure 2. The map shows that suitable climatic habitats of L. chinense were concentrated in Southeastern China, but also sporadically distributed across the northern coastal areas and the southwest border. Those suitable climatic habitats mainly include the southern parts of Liaoning, Beijing, Tianjin, Hebei, Anhui, Henan, Shaanxi, Guizhou, and Tibet; the northern parts of Zhejiang, Fujian, Jiangxi, Hubei, Hunan, Yunnan, Guangxi, Guangdong, and Taiwan; and Eastern Shandong.

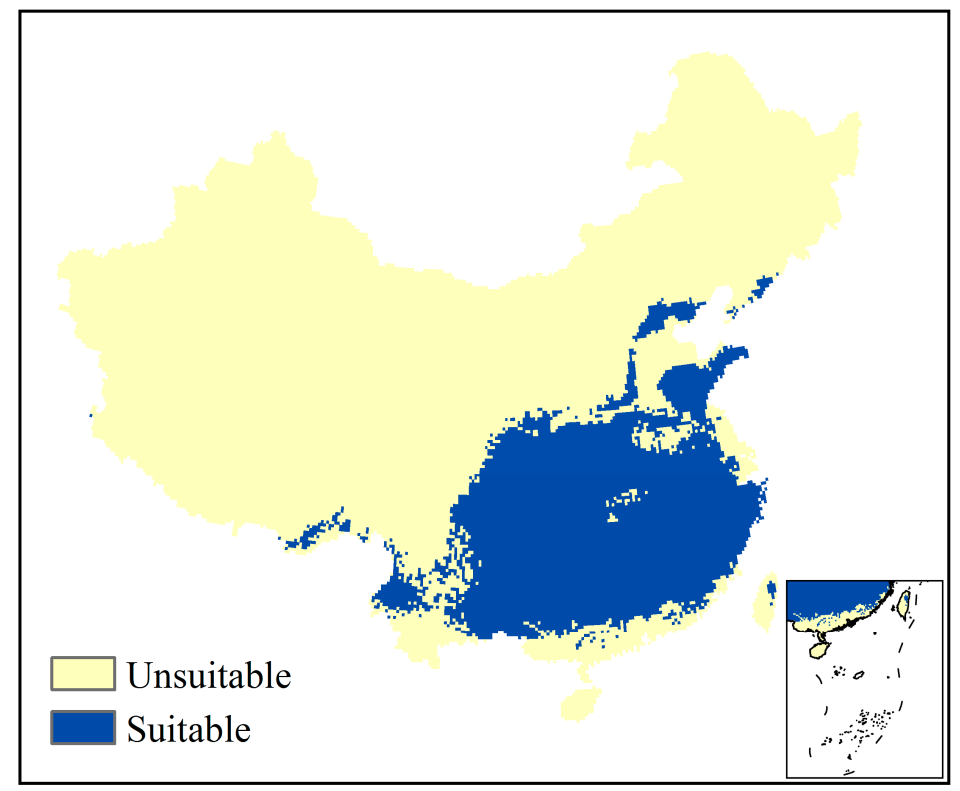

Figure 2. Current potential binary distribution of Liriodendron chinense in China.

\subsection{Future Potential Suitable Climatic Geographical Range}

The future potentially suitable climatic geographical range of L. chinense under different climate change scenarios was relatively stable compared to its current status (Figure 3). In both the 2050s and 2070s, the suitable climatic habitats were still centrally distributed in Southeastern China and sporadically distributed across the northern coastal areas (including the southern part of Liaoning, Beijing, Tianjin, and Hebei) and the southwest border (including the southern part of Guangxi and Tibet, as well as the northern part of Yunnan). However, the suitable climatic habitats showed a slight contraction in Anhui and Jiangxi under RCP 4.5-2070 (Figure 3d).

The area of suitable future climatic habitat of L. chinense under different climate change scenarios showed a relatively stable but slightly increasing trend in China (Table S9). Compared to its current suitable climatic habitat area $\left(2.22 \times 10^{6} \mathrm{~km}^{2}\right)$, the future suitable climatic habitat area of L. chinense increased by $6.7 \%, 6.9 \%, 7.8 \%$, and $8.7 \%$ under the RCP 2.6, RCP 4.5, RCP 6.0, and RCP 8.5 scenarios by the 2050s, respectively (Figure 4). By the 2070s, the suitable climatic habitat area continued to increase under the RCP 2.6 and RCP 8.5 scenarios, with increasing rates of $7.4 \%$ and $14.4 \%$, respectively. Those suitable climatic habitat gains were centrally distributed in the belt of Qinling Mountains-Taihang Mountains-Changbai Mountains (Figure S4). 

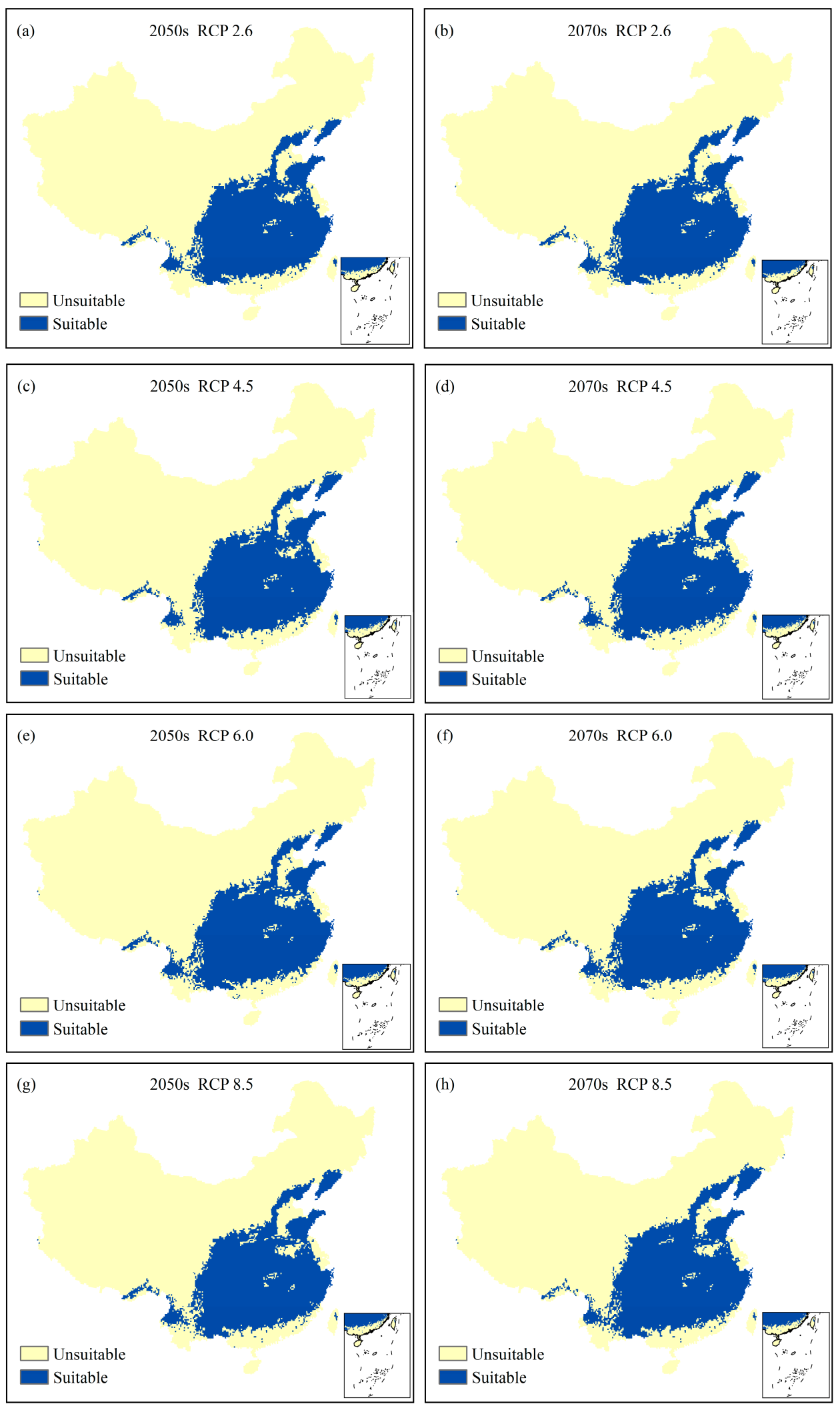

Figure 3. Potential binary distribution of Liriodendron chinense under different climate change scenarios in China. (a) 2050s in the Representative Concentration Pathway (RCP) 2.6 climate scenario, (b) 2070s in the RCP 2.6 climate scenario, (c) 2050s in the RCP 4.5 climate scenario, (d) 2070s in the RCP 4.5 climate scenario, (e) 2050s in the RCP 6.0 climate scenario, (f) 2070s in the RCP 6.0 climate scenario, (g) 2050s in the RCP 8.5 climate scenario, and (h) 2070s in the RCP 8.5 climate scenario. 


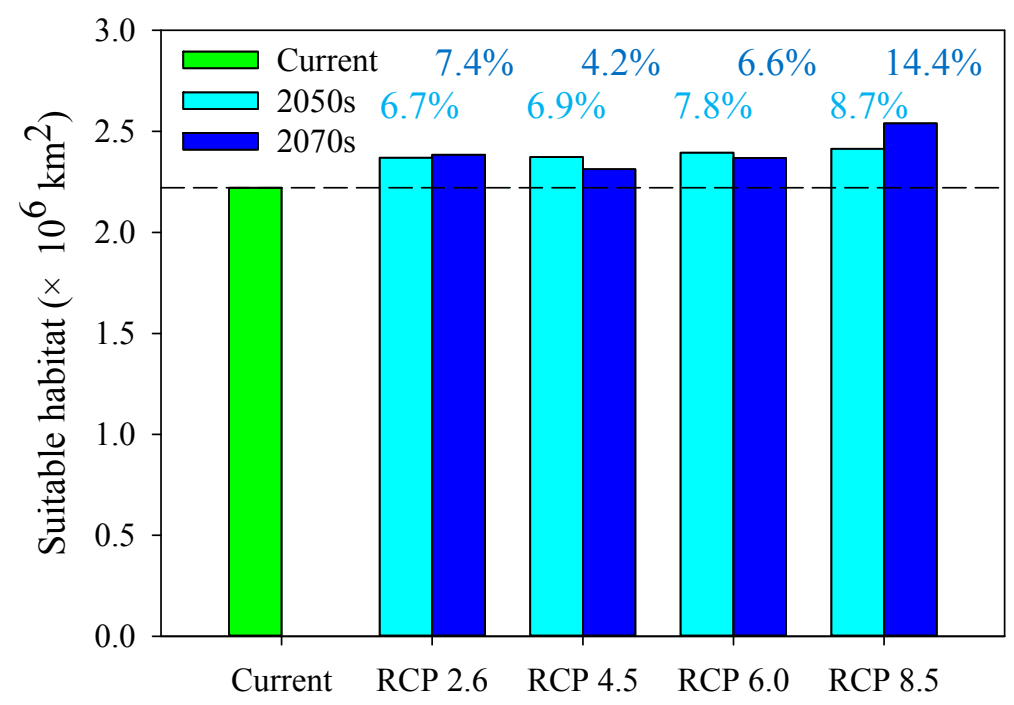

Climate change scenarios

Figure 4. Area of varying suitable climatic habitat of Liriodendron chinense under different climate change scenarios in China. Numbers indicate the percentage change in the area of suitable climatic habitat.

\subsection{Shifts in the Suitable Climatic Habitat}

The shifts in the suitable climatic habitat of L. chinense under different climate change scenarios are shown in Figure 5. The centroid $\left(111.25^{\circ} \mathrm{E}, 29.45^{\circ} \mathrm{N}\right)$ of its current suitable climatic habitat is located in Northern Hunan. Generally, the suitable climatic habitat centroid expressed a northward tendency under all four scenarios: RCP 2.6, RCP 4.5, RCP 6.0, and RCP 8.5. By the 2050s, the centroid of the suitable climatic habitat shifted $118.37 \mathrm{~km}$ northward under RCP 4.5. By the 2070s, the centroid moved $153.12 \mathrm{~km}$ northward under RCP 8.5 .

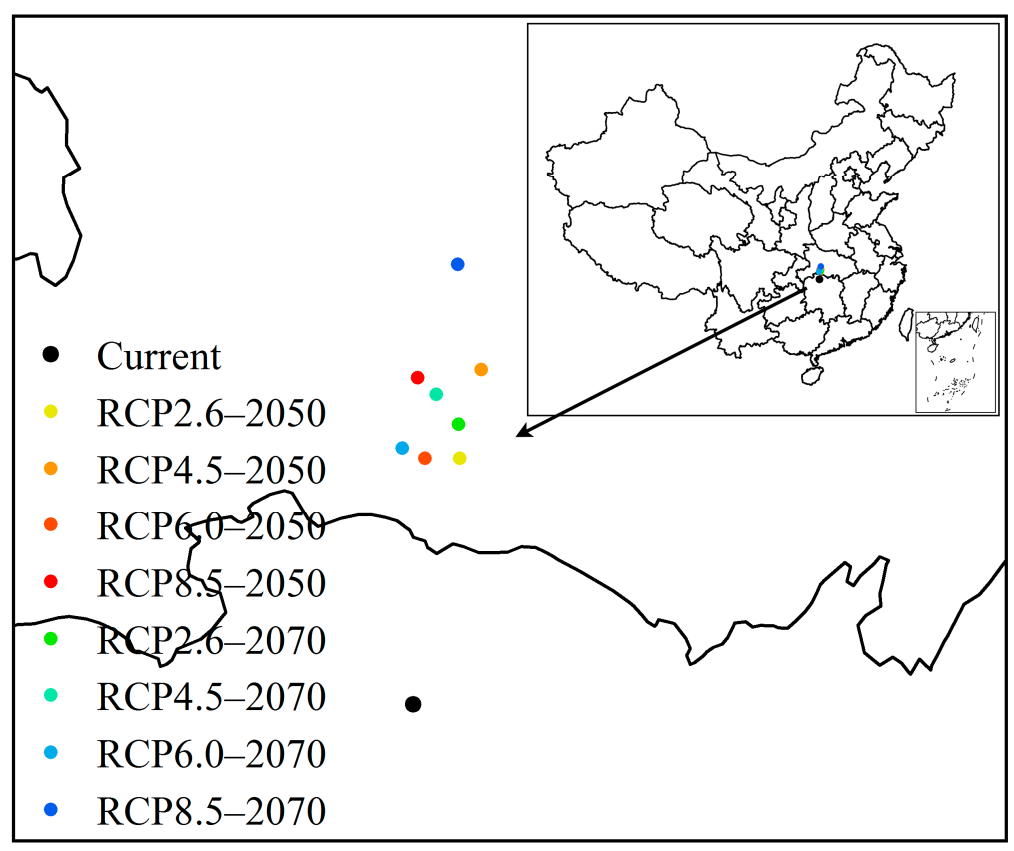

Figure 5. The shifts in the suitable climatic habitat of Liriodendron chinense under different climate change scenarios in China. Dots indicate the centroids of the suitable climatic habitat of L. chinense under current climate and different future climate scenario and timeframe combinations. 


\section{Discussion}

Identifying current and future species distribution is not only helpful for understanding the determinants of a species' distribution [60], but also crucial for initiating management strategies for habitat conservation and species sustainability to address climate change [61,62]. Species distribution model (SDM) is one of the most important tools for forecasting species distribution [63,64]. Using climatic and topographical variables on a large scale, MaxEnt has generated successful simulations of spatial distribution and ecological niches for various species [65]. In this study, MaxEnt also performed well for L. chinense in China, with a reasonably good AUC value of 0.912 , which is much better than the 0.5 of a random model.

Our model predicted that bioclimatic variables largely determined (94.1\%) the spatial distribution of L. chinense in China, while topographical variables only determined a very small part (5.9\%) (Table 1). This was consistent with the previous finding that climatic factors were much more important than topographical factors in determining the potential spatial distribution of species on a large scale $[66,67]$. AP (49.1\%) and TDQ (33.6\%) contributed the most to the spatial presence of L. chinense, and the most suitable AP and TDQ for L. chinense were around $1797 \mathrm{~mm}$ and $7.4{ }^{\circ} \mathrm{C}$, respectively (Figure S2). This indicates that $L$. chinense favors moist and moderate temperature environments, which agrees with the previous finding that the relative humidity from February to April and the mean temperature from January to April play essential roles in determining seed set in L. chinense [31]. In order to consider AP and TDQ simultaneously, we randomly selected $1 \%$ of the points from the current and future suitable climatic habitat of L. chinense, and then extracted the AP and TDQ values to those points using ArcGIS 10.3 (Figure S5). The scatter plot between the AP and TDQ values showed that regions with low TDQ and low AP and/or regions with high TDQ and high AP were suitable for L. chinense. This finding aligns with the characteristics of L. chinense, being deciduous and tall [31].

Numerous studies have proven that the global warming would have a negative effect on the populations, communities, and ecosystems [68,69]. For instance, Allen [70] found that increased global temperatures have negative influences on the distribution of woody plant species. Contrary to these studies, our study showed that climate warming would have positive effects on the suitable climatic habitat area of L. chinense, which was consistent with the study of the endangered medicinal plant (Homonoia riparia Lour) in Yunnan, China [46]. Compared to the belt distribution of the suitable climatic habitat gains of L. chinense, habitat losses were centrally distributed in an annular zone including Anhui and Jiangsu (Figure S4), indicating a threat to the natural distribution of L. chinense and an urgent need for conservation.

The suitable climatic habitat of $L$. chinense was predicted to shift northward, corresponding to the climate change in the next century (Figure 5). This finding was consistent with previous studies that have also found a northward shift in the spatial distribution of suitable species climatic habitat [44]. Species would shift their distributions to higher latitudes in response to warming climates, because temperature outside their thermal tolerance would decrease their capacity to survive [44,71-73]. Although the suitable climatic habitat of L. chinense was predicted to shift northward, those habitat gains may be inaccessible because of dispersal limitations. High mountains, such as the Qinling Mountains, are located at the northern boundaries of the suitable climatic habitat of L. chinense (Figure 3) and may therefore be a geographical barrier for the dispersion of L. chinense.

Despite finding an expansion in the suitable climatic habitat area of L. chinense with predicted future climate change, the stability and sustainability of its habitat will not be maintained unless conservation strategies are introduced for L. chinense. Several factors may be causing this threat, such as growth form, habitat specificity, and mode of reproduction, along with human impacts [65,74]. Among these factors, human influence is widely accepted to be one of the major drivers of the population decline [75]. Population expansion and city advancement have been driving people to occupy and destroy forests, which is the direct and critical reason for the reduction in the habitat of L. chinense. In addition, the leaves and barks of the plant are useful in pharmacy and the trunk is useful for furniture commercial use, driving people to harvest L. chinense excessively and extensively. 
The current and future potentially suitable climatic geographical range of L. chinense revealed in our study can help to identify sites for the reintroduction of the species and provide a scientific basis for future habitat management.

In this study, we explored how L. chinense responded geographically to climate change using MaxEnt modeling, a correlative model that only required readily available species' occurrence data and environmental information [18]. However, correlative models have been criticized because they are limited to a species' realized niche in a biological community [22]. The alternative ENM, the mechanistic model, determined species' fundamental niche by the physiology of organisms and thus could build a causal relationship between species distribution and interacting environmental variables [17]. Considering the respective advantages and limitations of both correlative and mechanistic models, future studies could integrate both models to provide a more accurate prediction of species responses to global climate change [17]. Physiological data derived from mechanistic models have been noted to be better parameters in correlative models than information derived from observed species occurrence records [17]. This study has left the issue of extending this combined modeling approach to future studies.

\section{Conclusions}

Liriodendron chinense is an important tertiary relict tree species with the urgent conservation demand. This study used the maximum entropy (MaxEnt) model to predict the potentially suitable climatic geographical range of L. chinense in China through integrating the observed occurrence records of $L$. chinense and corresponding climatic and topographical variables. Results of the MaxEnt model has identified the regions vulnerable to a threat of extinction and new areas for the potential introduction within the next half century, that can support conservation, restoration and management stratigies for L. chinense in China.

Supplementary Materials: The following are available online at www.mdpi.com/1999-4907/8/10/399/s1, Occurrence points of target species, selection of environmental factors, and so on are shown in Tables S1-S9 and Figures S1-S5.

Acknowledgments: We acknowledge with great appreciation the support provided by the National Special Water Programs (Grant No. 2017ZX07101-002, No. 2015ZX07203-011, No. 2015ZX07204-007, No. 2009ZX07210-009), Department of Environmental Protection of Shandong Province (SDHBPJ-ZB-08), and Chinese Natural Science Foundation (Grant No. 39560023). We thank three anonymous referees for their valuable comments that improved this manuscript.

Author Contributions: H.Z. designed the outline of this paper. Y.X. collected the data. X.X. completed the calculation using the MaxEnt model. X.X. and T.X. wrote the paper. L.Z. and W.T. analyzed data and gave some advice in the discussion.

Conflicts of Interest: The authors declare no conflict of interest.

\section{Abbreviations}

Beijing Climate Center Climate System Model

BCC-CSM1-1

Community Climate System Model

CCSM4

Goddard Institute for Space Studies Russell ocean model

GISS-E2-R

Institute Pierre Simon Laplace-Coupled Model 5A-Low Resolution

IPSL-CM5A-LR

Hadley Centre Global Environment Model 2-Earth System

HadGEM2-ES

Model for Interdisciplinary Research on Climate Earth System Model

MIROC-ESM-CHEM

Meteorological Research Institute

MRI-CGCM3

Norwegian Earth System Model

NorESM1-M

\section{References}

1. Pimm, S.L.; Russell, G.J.; Gittleman, J.L.; Brooks, T.M. The future of biodiversity. Science 1995, 269, 347-350. [CrossRef] [PubMed] 
2. Khanum, R.; Mumtaz, A.S.; Kumar, S. Predicting impacts of climate change on medicinal asclepiads of Pakistan using Maxent modeling. Acta Oecol. 2013, 49, 23-31. [CrossRef]

3. Lenoir, J.; Gégout, J.C.; Marquet, P.A.; de Ruffray, P.; Brisse, H. A significant upward shift in plant species optimum elevation during the 20th century. Science 2008, 320, 1768. [CrossRef] [PubMed]

4. Bertrand, R.; Lenoir, J.; Piedallu, C.; Riofríodillon, G.; de Ruffray, P.; Vidal, C.; Pierrat, J.C.; Gégout, J.C. Changes in plant community composition lag behind climate warming in lowland forests. Nature 2011, 479, 517. [CrossRef] [PubMed]

5. Dai, G.; Yang, J.; Huang, C.; Sun, C.; Jia, L.; Ma, L. The effects of climate change on the development of tree plantations for biodiesel production in China. Forests 2017, 8, 207. [CrossRef]

6. IPCC Summary for Policymakers. In Climate Change 2013: The Physical Science Basis. Contribution of Working Group I to the Fifth Assessment Report of the Intergovernmental Panel on Climate Change; Stocker, T.F.; Qin, D.; Plattner, G.-K.; Tignor, M.; Allen, S.K.; Boschung, J.; Nauels, A.; Xia, Y.; Bex, V.; Midgley, P.M., Eds.; Cambridge University Press: Cambridge, UK; New York, NY, USA.

7. Li, X.; Tian, H.; Wang, Y.; Li, R.; Song, Z.; Zhang, F.; Xu, M.; Li, D. Vulnerability of 208 endemic or endangered species in China to the effects of climate change. Reg. Environ. Change 2013, 13, 843-852. [CrossRef]

8. Saltré, F.; Duputié, A.; Gaucherel, C.; Chuine, I. How climate, migration ability and habitat fragmentation affect the projected future distribution of European beech. Glob. Change Biol. 2015, 21, 897. [CrossRef] [PubMed]

9. Guo, Y.; Li, X.; Zhao, Z.; Wei, H.; Gao, B.; Wei, G. Prediction of the potential geographic distribution of the ectomycorrhizal mushroom Tricholoma matsutake under multiple climate change scenarios. Sci. Rep. 2017, 7, 46221. [CrossRef] [PubMed]

10. Chakraborty, S.; Tiedemann, A.V.; Teng, P.S. Climate change: Potential impact on plant diseases. Environ. Pollut. 2000, 108, 317-326. [CrossRef]

11. Kumar, P. Assessment of impact of climate change on Rhododendrons in Sikkim Himalayas using Maxent modelling: Limitations and challenges. Biodivers. Conserv. 2012, 21, 1251-1266. [CrossRef]

12. Akhter, S.; Mcdonald, M.A.; van Breugel, P.; Sohel, S.; Kjær, E.D.; Mariott, R. Habitat distribution modelling to identify areas of high conservation value under climate change for Mangifera sylvatica Roxb. of Bangladesh. Land Use policy 2017, 60, 223-232. [CrossRef]

13. Rebelo, H.; Jones, G. Ground validation of presence-only modelling with rare species: A case study on barbastelles Barbastella barbastellus (Chiroptera: Vespertilionidae). J. Appl. Ecol. 2010, 47, 410-420. [CrossRef]

14. Peterson, A.T.; Soberón, J.; Pearson, R.G.; Anderson, R.P.; Martínezmeyer, E.; Nakamura, M. Ecological Niches and Geographic Distributions (Monographs in Population Biology No. 49); Princeton University Press: Princeton, NJ, USA, 2011.

15. Fourcade, Y.; Engler, J.O.; Rödder, D.; Secondi, J. Mapping species distributions with MAXENT using a geographically biased sample of presence data: A performance assessment of methods for correcting sampling bias. PLoS ONE 2014, 9, 1-13. [CrossRef] [PubMed]

16. Qin, A.; Liu, B.; Guo, Q.; Bussmann, R.W.; Ma, F.; Jian, Z.; Xu, G.; Pei, S. Maxent modeling for predicting impacts of climate change on the potential distribution of Thuja sutchuenensis Franch., an extremely endangered conifer from southwestern China. Glob. Ecol. Conserv. 2017, 10, 139-146. [CrossRef]

17. Monahan, W.B. A mechanistic niche model for measuring species' distributional responses to seasonal temperature gradients. PLoS ONE 2009, 4, e7921. [CrossRef] [PubMed]

18. Peterson, A.T.; Papeş, M.; Soberón, J. Mechanistic and correlative models of ecological niches. Eur. J. Ecol. 2015, 1, 28-38. [CrossRef]

19. Shabani, F.; Kumar, L.; Taylor, S. Distribution of date palms in the middle east based on future climate scenarios. Exp. Agric. 2015, 51, 244-263. [CrossRef]

20. Kearney, M.; Porter, W. Mechanistic niche modelling: Combining physiological and spatial data to predict species' ranges. Ecol. Lett. 2009, 12, 334-350. [CrossRef] [PubMed]

21. Shabani, F.; Kumar, L.; Ahmadi, M. A comparison of absolute performance of different correlative and mechanistic species distribution models in an independent area. Ecol. Evol. 2016, 6, 5973-5986. [CrossRef] [PubMed]

22. Jiménez-Valverde, A.; Lobo, J.M.; Hortal, J. Not as good as they seem: The importance of concepts in species distribution modelling. Divers. Distrib. 2008, 14, 885-890. [CrossRef] 
23. Wiens, J.A.; Stralberg, D.; Jongsomjit, D.; Howell, C.A.; Snyder, M.A. Niches, models, and climate change: Assessing the assumptions and uncertainties. Proc. Natl. Acad. Sci. USA 2009, 106, 19729-19736. [CrossRef] [PubMed]

24. Elith, J.; Leathwick, J.R. Species distribution models: Ecological explanation and prediction across space and time. Annu. Rev. Ecol. Evol. Syst. 2009, 40, 677-697. [CrossRef]

25. Phillips, S.J.; Dudík, M.; Schapire, R.E. A maximum entropy approach to species distribution modeling. In ICML 2004: Proceedings of the twenty-first international conference on Machine learning; ACM Press: New York, NY, USA, 2004; p. 83.

26. Phillips, S.J.; Anderson, R.P.; Schapire, R.E. Maximum entropy modeling of species geographic distributions. Ecol. Modell. 2006, 190, 231-259. [CrossRef]

27. Paquit, J.C.; Pampolina, N.M.; Tiburan, C.L.; Manalo, M.M.Q. Maxent modeling of the habitat distribution of the critically endangered Pterocarpus indicus Willd. forma indicus In Mindanao, Philippines. J. Biodivers. Environ. Sci. 2017, 2222-3045.

28. Li, G.; Xu, G.; Guo, K.; Du, S. Mapping the global potential geographical distribution of black locust (Robinia Pseudoacacia L.) using herbarium data and a maximum entropy model. Forests 2014, 5, 2773-2792. [CrossRef]

29. Wang, X.; Zheng, Q.; Yao, F.; Chen, Z.; Feng, Z.; Manning, W.J. Assessing the impact of ambient ozone on growth and yield of a rice (Oryza sativa L.) and a wheat (Triticum aestivum L.) cultivar grown in the Yangtze Delta, China, using three rates of application of ethylenediurea (EDU). Environ. Pollut. 2007, 148, 390-395. [CrossRef] [PubMed]

30. Tang, C.Q.; Robertson, K. Survival of a tertiary relict species, Liriodendron chinense (Magnoliaceae), in southern China, with special reference to village fengshui forests. Am. J. Bot. 2013, 100, 2112. [CrossRef] [PubMed]

31. Hao, R.M.; He, S.A. Geographical distribution of Liriodederon chinense in China and its significance. J. Plant Resour. Environ. 1995.

32. Shang, K.K.; Song, K.; Da, L.J. Ecology of Relict Tertiary Deciduous Trees in Subtropical China; Springer International Publishing: Cham, Switzerland, 2016.

33. Zhang, W.W.; Niu, J.F.; Wang, X.K.; Tian, Y.; Yao, F.F.; Feng, Z.Z. Effects of ozone exposure on growth and photosynthesis of the seedlings of Liriodendron chinense (Hemsl.) Sarg, a native tree species of subtropical China. Photosynthetica 2011, 49, 29-36. [CrossRef]

34. Wang, S. China species red list; Higher Education Press: Beijing, China, 2004.

35. Yao, X.; Zhang, J.; Ye, Q.; Huang, H. Characterization of 14 novel microsatellite loci in the endangered Liriodendron chinense (Magnoliaceae) and cross-species amplification in closely related taxa. Conserv. Genet. 2008, 9, 483-485. [CrossRef]

36. Zhang, M.-G.; Slik, J.W.F.; Ma, K.-P. Using species distribution modeling to delineate the botanical richness patterns and phytogeographical regions of China. Nat. Publ. Gr. 2016, 1-9. [CrossRef] [PubMed]

37. Zhang, Y.; Wang, Y.; Zhang, M.; Ma, K. Climate change threats to protected plants of China: An evaluation based on species distribution modeling. Chinese Sci. Bull. 2014, 59, 4652-4659. [CrossRef]

38. Qin, Z.; DiTommaso, A.; Wu, R.S.; Huang, H.Y. Potential distribution of two Ambrosia species in China under projected climate change. Weed Res. 2014, 54, 520-531. [CrossRef]

39. Li, G.; Xu, G.; Guo, K.; Du, S. Geographical boundary and climatic analysis of Pinus tabulaeformis in China: Insights on its afforestation. Ecol. Eng. 2016, 86, 75-84. [CrossRef]

40. Radosavljevic, A.; Anderson, R.P. Making better Maxent models of species distributions: Complexity, overfitting and evaluation. J. Biogeogr. 2014, 41, 629-643. [CrossRef]

41. Hijmans, R.J.; Cameron, S.E.; Parra, J.L.; Jones, P.G.; Jarvis, A. Very high resolution interpolated climate surfaces for global land areas. Int. J. Climatol. 2005, 25, 1965-1978. [CrossRef]

42. Oke, O.A.; Heard, S.B.; Lundholm, J.T. Integrating phylogenetic community structure with species distribution models: An example with plants of rock barrens. Ecography 2014, 37, 614-625. [CrossRef]

43. Araújo, M.B.; New, M. Ensemble forecasting of species distributions. Trends Ecol. Evol. 2007, 22, 42-47. [CrossRef] [PubMed]

44. Manish, K.; Telwala, Y.; Nautiyal, D.C.; Pandit, M.K. Modelling the impacts of future climate change on plant communities in the Himalaya: A case study from Eastern Himalaya, India. Model. Earth Syst. Environ. 2016, 2, 1-12. [CrossRef] 
45. Pearson, R.G.; Raxworthy, C.J.; Nakamura, M.; Peterson, A.T. Predicting species distributions from small numbers of occurrence records: A test case using cryptic geckos in Madagascar. J. Biogeogr. 2007, 34, 102-117. [CrossRef]

46. Yi, Y.J.; Cheng, X.; Yang, Z.F.; Zhang, S.H. Maxent modeling for predicting the potential distribution of endangered medicinal plant (H. riparia Lour) in Yunnan, China. Ecol. Eng. 2016, 92, 260-269. [CrossRef]

47. Aguirre-Gutiérrez, J.; Carvalheiro, L.G.; Polce, C.; van Loon, E.E.; Raes, N.; Reemer, M.; Biesmeijer, J.C. Fit-for-purpose: Species distribution model performance depends on evaluation criteria-Dutch hoverflies as a case study. PLoS ONE 2013, 8, e63708. [CrossRef] [PubMed]

48. Heikkinen, R.K.; Luoto, M.; Araújo, M.B.; Virkkala, R.; Thuiller, W.; Sykes, M.T. Methods and uncertainties in bioclimatic envelope modelling under climate change. Prog. Phys. Geogr. 2006, 30, 751-777. [CrossRef]

49. He, S.A.; Hao, R.M. Study on the natural population dynamics and the endangering habitat of Liriodendron chinense in China. Acta Phytoecol. Sin. 1999, 23, 87-95.

50. Yang, A.; Dick, C.W.; Yao, X.; Huang, H. Impacts of biogeographic history and marginal population genetics on species range limits: A case study of Liriodendron chinense. Sci. Rep. 2016, 6. [CrossRef] [PubMed]

51. Phillips, S.J.; Dudík, M. Modeling of species distributions with Maxent: New extensions and a comprehensive evaluation. Ecography 2008, 31, 161-175. [CrossRef]

52. Narouei-Khandan, H.A.; Halbert, S.E.; Worner, S.P.; van Bruggen, A.H.C. Global climate suitability of citrus huanglongbing and its vector, the Asian citrus psyllid, using two correlative species distribution modeling approaches, with emphasis on the USA. Eur. J. Plant Pathol. 2016, 144, 655-670. [CrossRef]

53. Priti, H.; Aravind, N.A.; Uma Shaanker, R.; Ravikanth, G. Modeling impacts of future climate on the distribution of Myristicaceae species in the Western Ghats, India. Ecol. Eng. 2016, 89, 14-23. [CrossRef]

54. Shcheglovitova, M.; Anderson, R.P. Estimating optimal complexity for ecological niche models: A jackknife approach for species with small sample sizes. Ecol. Modell. 2013, 269, 9-17. [CrossRef]

55. Warren, D.L.; Seifert, S.N. Ecological niche modeling in Maxent: The importance of model complexity and the performance of model selection criteria. Ecol. Appl. 2011, 21, 335-342. [CrossRef] [PubMed]

56. Morales, N.S.; Fernández, I.C.; Baca-González, V. MaxEnt's parameter configuration and small samples: Are we paying attention to recommendations? A systematic review. PeerJ 2017, 5, e3093. [CrossRef] [PubMed]

57. Manel, S.; Williams, H.C.; Ormerod, S.J. Evaluating Presence-Absence Models in Ecology: The Need to Account for Prevalence. J. Appl. Ecol. 2001, 38, 921-931. [CrossRef]

58. Jiménez-Valverde, A.; Lobo, J.M. Threshold criteria for conversion of probability of species presence to either-or presence-absence. Acta Oecologica 2007, 31, 361-369. [CrossRef]

59. Aguirre-Gutiérrez, J.; Kissling, W.D.; Carvalheiro, L.G.; WallisDeVries, M.F.; Franzén, M.; Biesmeijer, J.C. Functional traits help to explain half-century long shifts in pollinator distributions. Sci. Rep. 2016, 6. [CrossRef] [PubMed]

60. Davies, T.J.; Purvis, A.; Gittleman, J.L. Quaternary climate change and the geographic ranges of mammals. Am. Nat. 2009, 174, 297. [CrossRef] [PubMed]

61. Sinclair, S.J.; White, M.D.; Newell, G.R. How useful are species distribution models for managing biodiversity under future climates? Ecol. Soc. 2010, 15, 299-305. [CrossRef]

62. Porfirio, L.L.; Harris, R.M.; Lefroy, E.C.; Hugh, S.; Gould, S.F.; Lee, G.; Bindoff, N.L.; Mackey, B. Improving the use of species distribution models in conservation planning and management under climate change. PLoS ONE 2014, 9, e113749. [CrossRef] [PubMed]

63. Wisz, M.S.; Hijmans, R.J.; Li, J.; Peterson, A.T.; Graham, C.H.; Guisan, A. Effects of sample size on the performance of species distribution models. Divers. Distrib. 2008, 14, 763-773. [CrossRef]

64. Remya, K.; Ramachandran, A.; Jayakumar, S. Predicting the current and future suitable habitat distribution of Myristica dactyloides Gaertn. using MaxEnt model in the Eastern Ghats, India. Ecol. Eng. 2015, 82, 184-188. [CrossRef]

65. Ranjitkar, S.; Xu, J.; Shrestha, K.K.; Kindt, R. Ensemble forecast of climate suitability for the Trans-Himalayan Nyctaginaceae species. Ecol. Modell. 2014, 282, 18-24. [CrossRef]

66. Guisan, A.; Tingley, R.; Baumgartner, J.B.; Naujokaitis-Lewis, I.; Sutcliffe, P.R.; Tulloch, A.I.T.; Regan, T.J.; Brotons, L.; McDonald-Madden, E.; Mantyka-Pringle, C.; et al. Predicting species distributions for conservation decisions. Ecol. Lett. 2013, 16, 1424-1435. [CrossRef] [PubMed] 
67. Li, G.; Sheng, D.; Wen, Z. Mapping the climatic suitable habitat of oriental arborvitae (Platycladus orientalis) for introduction and cultivation at a global scale. Sci. Rep. 2016, 6, 30009. [CrossRef] [PubMed]

68. Monteith, K.L.; Klaver, R.W.; Hersey, K.R.; Holland, A.A.; Thomas, T.P.; Kauffman, M.J. Effects of climate and plant phenology on recruitment of moose at the southern extent of their range. Oecologia 2015, 178, 1137. [CrossRef] [PubMed]

69. Thomas, C.D.; Cameron, A.; Green, R.E.; Bakkenes, M.; Beaumont, L.J.; Collingham, Y.C.; Erasmus, B.F.N.; De Siqueira, M.F.; Grainger, A.; Hannah, L.; et al. Extinction risk from climate change. Nature 2004, 427, 145-148. [CrossRef] [PubMed]

70. Allen, C.D. Climate-induced forest dieback: An escalating global phenomenon? Unasylva 2009, 60, 43-49.

71. Nilsson, S.; Pitt, D.C. Mountain World in Danger: Climate Change in the Forests and Mountains of Europe; Earthscan Publications Ltd.: London, UK, 1991.

72. Grabherr, G.; Gottfried, M.; Pauli, H. Climate effects on mountain plants. Nature 1994, 369, 448. [CrossRef] [PubMed]

73. Brusca, R.C.; Wiens, J.F.; Meyer, W.M.; Eble, J.; Franklin, K.; Overpeck, J.T.; Moore, W. Dramatic response to climate change in the Southwest: Robert Whittaker's 1963 Arizona Mountain plant transect revisited. Ecol. Evol. 2013, 3, 3307-3319. [CrossRef] [PubMed]

74. Ranjitkar, S.; Kindt, R.; Sujakhu, N.M.; Hart, R.; Wen, G.; Yang, X.; Shrestha, K.K.; Xu, J.; Luedeling, E. Separation of the bioclimatic spaces of Himalayan tree rhododendron species predicted by ensemble suitability models. Glob. Ecol. Conserv. 2014, 1, 2-12. [CrossRef]

75. Ghimire, S.K.; Sapkota, I.B.; Oli, B.R.; Rai-Parajuli, R. Non-Timber Forest Products of Nepal Himalaya: Database of Some Important Species Found in the Mountain Protected Areas and Surrounding Regions; WWF Nepal: Kathmandu, Nepal, 2008.

(C) 2017 by the authors. Licensee MDPI, Basel, Switzerland. This article is an open access article distributed under the terms and conditions of the Creative Commons Attribution (CC BY) license (http:/ / creativecommons.org/licenses/by/4.0/). 